\title{
ADULT POST OPERATIVE JEJUNOJEJUNAL INTUSSUSCEPTION FOLLOWING TOTAL TRUNCAL VAGOTOMY WITH POSTERIOR VERTICAL RETROCOLIC ISOPERISTALITIC NO LOOP GASTROJEJUNOSTOMY
}

Shashidhara $\mathrm{P}^{1}$, Puneetha $\mathrm{K}^{2}$, Seshasayi $\mathrm{M}^{3}$

\section{HOW TO CITE THIS ARTICLE:}

Shashidhara P, Puneetha K, Seshasayi M. "Adult post- operative Jejunojejunal Intussusception following total Truncal Vagotomy with Posterior Vertical Retrocolic Isoperistalitic no Loop Gastrojejunostomy". Journal of Evolution of Medical and Dental Sciences 2014; Vol. 3, Issue 62, November 17; Page: 13765-13768, DOI: $10.14260 /$ jemds/2014/3839

ABSTRACT: Intussusception which is a common entity in pediatric age group is a rare condition among adults and accounts for only about $5 \%$ of all cases of intussusceptions. In adults about $90 \%$ of cases have a definitive etiology like tumor, post-operative conditions, etc.(1) We report a case of ante grade jejunojejunal intussusception in a 58 year old male who had undergone Total truncal vagotomy with Posterior Vertical Retrocolic Isoperistalitic No loop Gastrojejunostomy.

KEYWORDS: Adult antegrade jejunojejunal intussusceptions; Posterior Gastrojejunostomy.

CASE REPORT: A 58-year-old male patient underwent an uneventful Total Truncal Vagotomy with Posterior Vertical Retrocolic Isoperistalitic No loop Gastrojejunostomy for peptic ulcer in 1 ${ }^{\text {st }}$ part of duodenum. Ryle's tube was kept for 4 days and the patient was put on oral fluids from $5^{\text {th }}$ day. On $8^{\text {th }}$ post-operative day he presented with history of sudden onset colicky upper abdominal pain and vomiting. Clinical examination was unremarkable.

The patient's symptoms resolved following a day of conservative management consisting of nil orally and intravenous fluids following which he was started on a liquid diet. He again complained of severe colicky abdominal pain with bilious vomiting.

Clinical examination revealed abdominal fullness without visible peristalsis. X-ray abdomen revealed dilated proximal small bowel loops, with significant air-fluid levels. Ultrasound abdomen revealed gastric dilatation with dilated proximal small bowel loops with target sign in jejunal loops, CT abdomen revealed jejunojejunal intussusceptions and patient was immediately taken for emergency laparotomy.

At emergency laparotomy, stomach was distended with distension of proximal jejunum. We found an ante grade jejunojejunal intussusception $40 \mathrm{~cm}$ away from the duodenojejunal flexure and $20 \mathrm{~cm}$ away from the gastrojejunostomy site. Intussusception was reduced by gently milking out the invaginated segment of jejunum.

While the proximal portion of the invaginated jejunum (intussusceptum) could be reduced easily, but dissection of adhesions between terminal segment of the intussusceptum and the intussuscepiens was required to reduce the intussusceptions completely. Presumably, these adhesions acted as a lead point and initiated the process of intussusception in this patient. His recovery was uneventful and he was discharged on the tenth post-operative day on a normal diet 


\section{CASE REPORT}

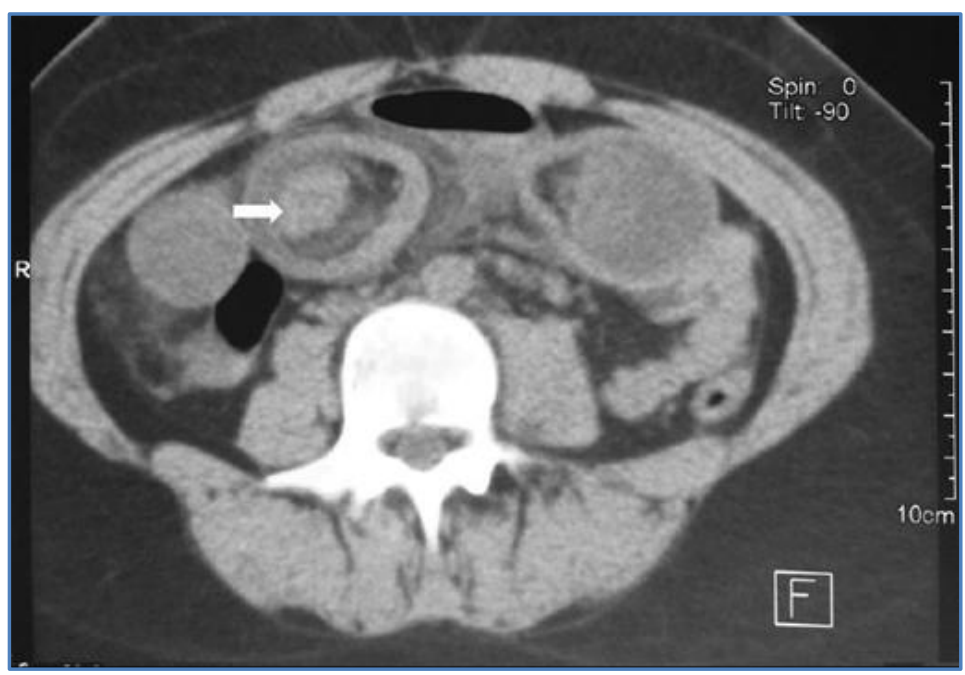

CT picture showing cross section of abdomen (arrow pointing the site of intussusception)

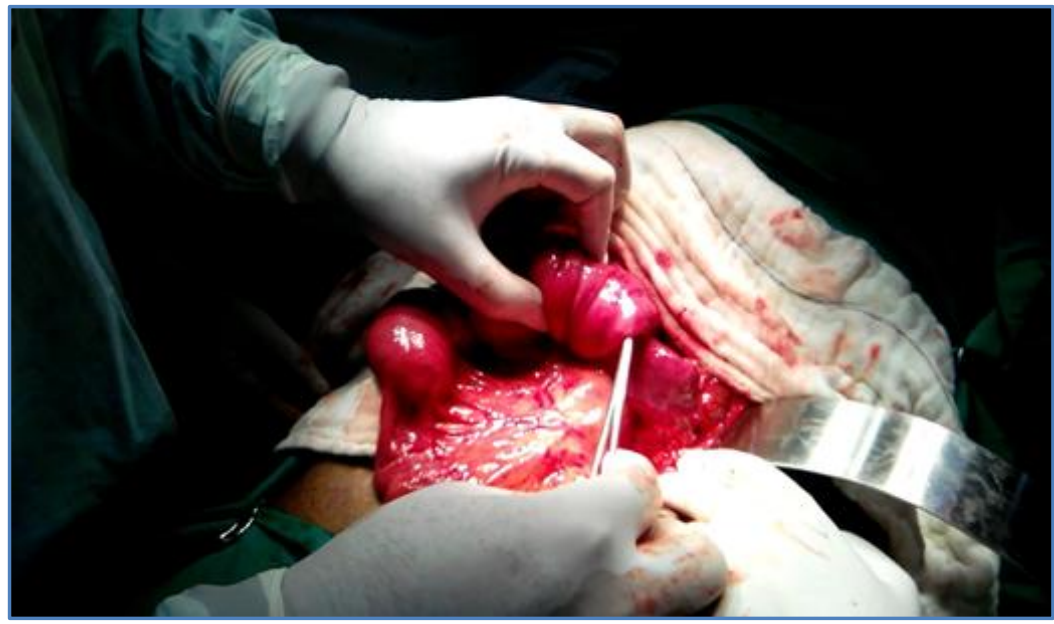

Intra operative picture our patient showing antegrade jejunojejunal intussusception distal to gastrojejunostomy site, intussusceptions showed by pointing at the invaginated jejunal loop

DISCUSSION: Intussusception, the telescoping of a segment of bowel loop into another is one of the leading causes of intestinal obstruction in children. But it is rare in adults, accounting for $<1 \%$ of all cases of small bowel obstruction and 5\% of all cases of intussusceptions. ${ }^{[1]}$ Agha et al[2] categorized intussusception into four groups namely, a) tumor-related, b) post-operative, c) miscellaneous, and d) idiopathic.[2]

Post-operative intussusception is very rare in adults and recognized as a distinct entity. Its etiology may be idiopathic or secondary to various predisposing factors like suture lines, adhesions, submucosal bowel edema, intestinal dysmotility, long intestinal tubes and chronic dilatation of 
bowel.[2] Idiopathic post-operative intussusception is extremely rare, may occur without lead points and most frequently follows Billroth II partial gastrectomy with gastrojejunostomy and intussusception of the excluded segment after jejunoileal bypass for morbid obesity.[2,3] It has also been reported less frequently after Roux-en-Y gastrojejunostomy,[4] truncal vagotomy,[5] pancreaticoduodenectomy, ${ }^{[6]}$ abdominal trauma surgery, ${ }^{[7]}$ gynecological surgery, ${ }^{[8]}$ jejunostomy,[9] appendicectomy.[10] Antegrade jejunojejunal intussusception after posterior gastrojejunostomy is a very rare post-gastrojejunostomy gastrointestinal complication and not been reported even in large series of patients who underwent gastrojejunostomy.[11-13]

Reymond postulated two mechanisms for intussusception. First, it may propagate from a functionally non-contractile inhomogeneous part of the intestinal wall, recognized as an indurated area or a region of diameter change in the bowel forming a flaccid motile interface or secondly, any mechanical linkage of two nonadjacent bowel segment with either an intraluminal (polyp) or extraluminal (postoperative adhesion) leadpoint.[14] Feeding jejunostomy as a cause for jejunojejunal intussusception following esophagectomy has been reported. In our patient, there was no leadpoint no feeding jejunostomy tube; we found intra-operatively that the intussusception was $20 \mathrm{~cm}$ away from the gastrojejunostomy site. Post-operative adhesions between the loops probably served as an extraluminal factor, as in Reymond's theory and acted as a pathological lead point for the ante grade jejunojejunal intussusception.

The classical clinical trial of intussusception namely pain abdomen, palpable sausage shaped mass and red currant jelly stools, is rare in adults. While adult and pediatric postoperative intussusception shares the same clinical presentation such as pain abdomen, nausea and vomiting,[15] Nausea, vomiting, gastrointestinal bleeding, change in bowel habits, constipation or abdominal distension are the nonspecific symptoms and signs of intussusceptions. Variability in clinical presentation and imaging features often make the preoperative diagnosis of intussusceptions a challenging and difficult task.

Idiopathic post-operative intussusception in adults occurs in the age between 45 to 50 years and is common on the 4th or 5th post-operative day with jejunojejunal intussusception being the most common type, ${ }^{[4]}$ whereas post-operative intussusception following various predisposing factors such as suture line adhesions etc. presents late after abdominal surgery.

\section{REFERENCES:}

1. Azar T, Berger DL. Adult intussusception. Ann Surg. 1997; 226:134-8.

2. Agha FP. Intussusception in adults. AJR Am J Roentgenol. 1986; 146: 527-31.

3. Kjellstrom BT, Gortz L, Nilsson S. Adult idiopathic enteric intussusceptions in the postoperative period. Case report. Eur J Surg. 1991; 157: 359-60.

4. Loizou MC, Koundourakis SS, Kollias VD, Panayotides HC, Papagrigoriadis SS. Jejunojejunal intussusceptions after Rouxen-Y gastrojejunostomy: a rare cause of postoperative bowelobstruction in an adult. Case report. Eur J Surg. 1994; 160: 451-2.

5. Zbar AP, Murphy F, Krishna SM. Adult postoperative intussusception: a rare cause of small bowel obstruction. South Med J. 2007; 100: 1042-4.

6. Sedgwick CE, Vernon JK. Jejunojejunal intussusception. An unusual complication after pancreatoduodenectomy. Am J Surg. 1970; 119: 752-3. 
7. Duncan A, Phillips TF, Sclafani SJ, Goldstein AS, Lipkowitz G, Scalea TM, et al. Intussusception following abdominal trauma. J Trauma. 1987; 27: 1193-9.

8. Hunter JG, Schwartz ME, Kim US. Postoperative intussusception after vaginal vault suspension. Am J Obstet Gynecol. 1986; 154: 633-4.

9. Wu TH, Lin CW, Yin WY. Jejunojejunal intussusceptions following jejunostomy. J Formos Med Assoc. 2006; 105: 355-8.

10. Wolfson S, Shachor D, Freund U. Ileocolic intussusceptions in an adult. A postoperative complication of appendectomy. Dis Colon Rectum. 1984; 27: 265-6.

11. Orringer MB, Marshall B, Chang AC, Lee J, Pickens A, Lau CL. Two thousand transhiatal esophagectomies: changing trends, lesson learned. Ann Surgery. 2007; 246: 363-72; discussion372-4.

12. Hulscher JB, Tijssen JG, Obertop H, Van Lanschot JJ. Transthoracic versus transhiatal resection for carcinoma of the esophagus: a meta-analysis. Ann Thoracic Surgery. 2001; 72: 306-13.

13. Hulscher JB, van Sandick JW, de Boer AG, Wijnhoven BP, Tijssen JG, Fockens P, et al. Extended transthoracic resection compared with limited transhiatal resection for adenocarcinoma of the esophagus. N Engl J Med. 2002; 347: 1662-9.

14. Reymond RD. The mechanism of intussusceptions: a theoretical analysis of the phenomenon. $\mathrm{Br}$ J Radiol. 1972; 45:1-7.

15. Saar MG, Nagorney DM, Mcllrath DC. Postoperative intussusception in adult: a previously unrecognized entity? Arch Surg. 1981; 116: 144-8.

\section{AUTHORS:}

1. Shashidhara P.

2. Puneetha K.

3. Seshasayi M.

\section{PARTICULARS OF CONTRIBUTORS:}

1. Assistant Professor, Department of Surgery, RRMCH, Bangalore.

2. Post Graduate, Department of Surgery, RRMCH, Bangalore.

3. Professor, Department of Surgery, RRMCH, Bangalore.

\section{NAME ADDRESS EMAIL ID OF THE} CORRESPONDING AUTHOR:

Dr. Shashidhara $P$, $33 / 1,1^{\text {st }}$ ' ${ }^{\prime}$ ' Cross, $5^{\text {th }}$ Block, Banashankari $3^{\text {rd }}$ Stage, Bangalore-560085.

Email: dr.shashi85@gmail.com

Date of Submission: 02/11/2014.

Date of Peer Review: 03/11/2014.

Date of Acceptance: 12/11/2014.

Date of Publishing: 17/11/2014. 